\title{
Experimental and numerical investigations of natural convection phenomena in a fermentation tank
}

Daniel KLEMBT, Heiko MEIRONKE

DOI: 10.30464/jmee.2019.3.3.235

Cite this article as:

Klembt D., Meironke H., Experimental and numerical investigations of natural convection phenomena in a fermentation tank. Journal of Mechanical and Energy Engineering, Vol. 3(43), No. 3, 2019, pp. 235-244.

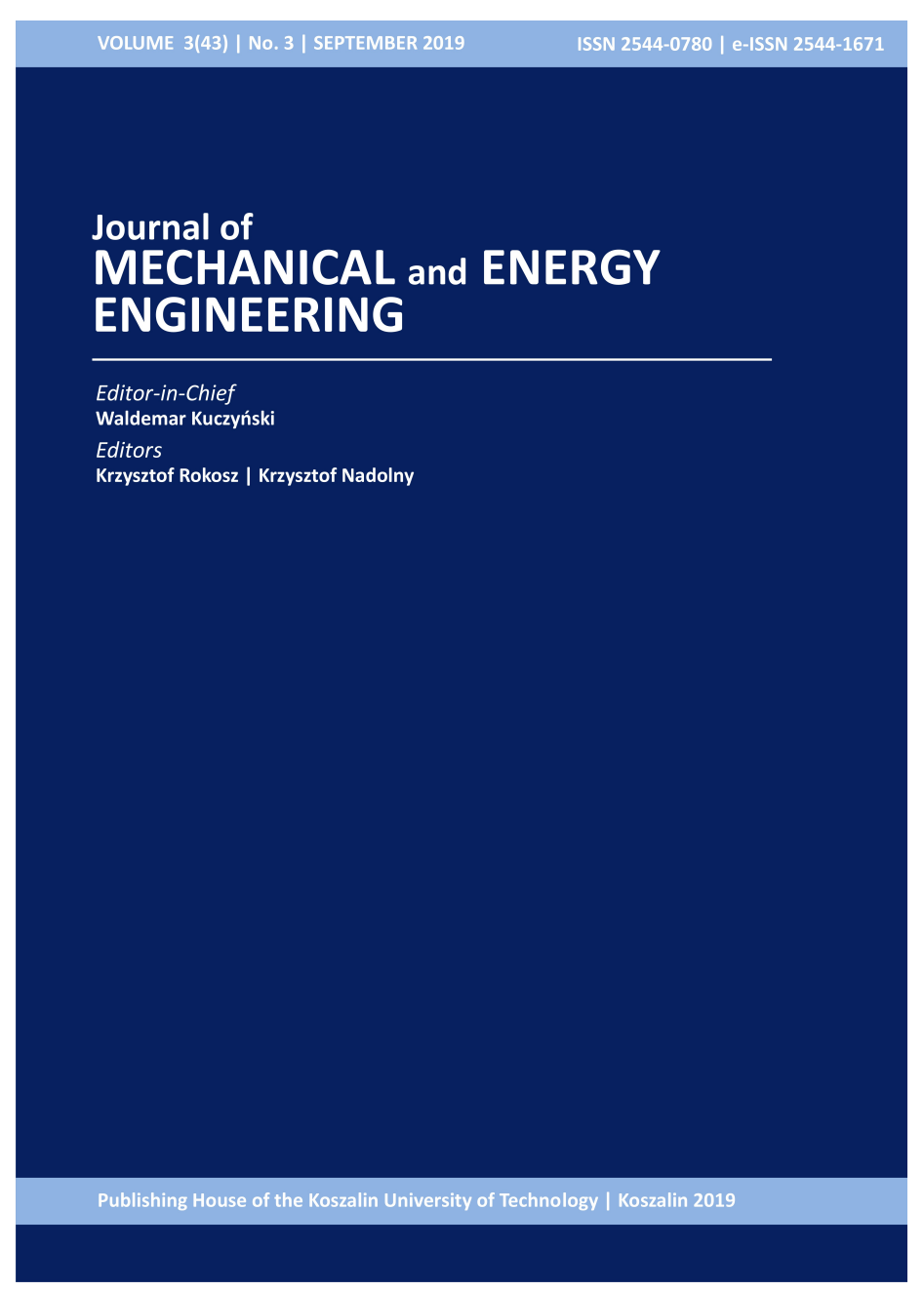

\section{Journal of Mechanical and Energy} Engineering

Website: jmee.tu.koszalin.pl

ISSN (Print): 2544-0780

ISSN (Online): 2544-1671

Volume: 3(43)

Number: 3

Year: 2019

Pages: 235-244

Article Info:

Received 22 November 2019

Accepted 3 December 2019

\section{Open Access}

This article is distributed under the terms of the Creative Commons Attribution 4.0 (CC BY 4.0) International License (http://creativecommons.org/licenses/by/4.0/), which permits unrestricted use, distribution, and reproduction in any medium, provided you give appropriate credit to the original author(s) and the source, provide a link to the Creative Commons license, and indicate if changes were made. 


\title{
EXPERIMENTAL AND NUMERICAL INVESTIGATIONS OF NATURAL CONVECTION PHENOMENA IN A FERMENTATION TANK
}

\author{
Daniel KLEMBT ${ }^{1 *}$, Heiko MEIRONKE ${ }^{2}$ \\ 1* Faculty of Mechanical Engineering, Department of Fluid Mechanics and Apparatus Engineering, \\ University of Applied Science Stralsund, Zur Schwedenschanze 15, 18435, Stralsund, Germany, \\ e-mail: daniel.klembt@hochschule-stralsund.de \\ ${ }^{2}$ Faculty of Mechanical Engineering, Department of Fluid Mechanics and Apparatus Engineering, \\ University of Applied Science Stralsund, Zur Schwedenschanze 15, 18435, Stralsund, Germany, \\ e-mail: heiko.meironke@hochschule-stralsund.de
}

(Received 6 December 2019, Accepted 3 December 2019)

\begin{abstract}
In the context of investigations of real multiphase flows, the university has its own 350 litre fermentation tank with comprehensive acoustic flow and temperature measurement technology for the systematically investigation, of the influence of the fermentation activity, distribution of yeast and occurring convection phenomena. Due to the many problems with the optical (e.g. PIV) and acoustic (e.g. UDV) measurement in a real fermenting fluid the numerical simulation was already used in earlier publications. To validate the numerical models, extensive experimental investigations were carried out which show that the flow in the fermenter is caused only by the reaction products of the yeast and the cooling panels and controls the yeast distribution. In this paper, both the numerical (CFD) and the experimental investigations serve as a starting point to influence the yeast distribution. The described convection flow can only temporarily guarantee the uniform distribution of the yeast in the fermenter until the sedimentation of the yeast at the tank bottom (bottom-fermenting yeast) finally begins. The aim of the investigation is to influence the convection flow in certain zones by targeted cooling or heating of the jackets in such a way that a uniform spatial distribution of the yeast over the entire fermentation process is ensured and thus optimal conditions for its metabolic processes are given. Finally, the numerical simulation is validated with the experimental data.
\end{abstract}

Keywords: ultrasonic doppler velocimetry, numerical simulation, natural convection flow

\section{INTRODUCTION}

The brewing trade has a long tradition in Germany. In 1516, the oldest food law in the world was proclaimed with the German Beer Purity Law "Reinheitsgebot".

There are over 1400 active breweries in Germany, the number of which could rise to 1500 by 2020 according to the German Brewers Association. With an annual turnover in 2017 of around 7.38 billion euros by the German beer producers, this branch of the economy cannot be neglected. While the breweries have optimised almost all processes from procurement to filling, there is still a need for optimisation in the actual main process, the fermentation. A targeted thermal influence on the flow inside the fermentation and storage tanks could promise economic advantages [1].

In cooperation with the local brewery, the Department of Fluid Mechanics and Apparatus Engineering of the University of Applied Sciences Stralsund investigates flow processes and phenomena in fermentation and storage tanks, especially during the fermentation, maturation and storage of beer [2-5]. One of the most important processes in the production of beer is the fermentation (sugar and yeast ferment to alcohol and carbon dioxide). During the biochemical reaction of fermentation, the fluid heats up (exothermic reaction). Without cooling, the conversion of substances would be increasingly accelerated by the Van 't Hoff equation and from a temperature of $45^{\circ} \mathrm{C}$ 
the denaturation of the proteins and thus the death of the yeast would begin. The ideal process temperature for production is 8 to 10 degrees Celsius (cold fermentation) or 12 to 14 degrees Celsius (warm fermentation) [6]. The heat resulting from the yeast reaction and the cooling of the tank generates a natural convection flow, which is superimposed by a gas bubble flow also produced during fermentation.

Both the natural convection flow and convection flow induced by gas bubbles transport the yeast in the tank [7]. However, the natural convection flow can only prevent the sedimentation of the yeast at the bottom of the tank (bottom-fermented yeast) for a short time. By targeted cooling or heating of the cooling jackets, the convection flow in certain zones could be influenced in such a way that a uniform spatial distribution of the yeast over the entire fermentation process can be ensured and thus optimum conditions for its metabolic processes are given [8]. An automated real-time control of the cooling/heating jackets based on the experimental and numerical results could lead to shorter process times in the fermentation process and thus considerable cost savings.

In this paper, the idea is to develop a heating circuit and subsequently integrate it into the existing cooling circuit of the fermentation and storage tank in the laboratory. This way a zone by zone real-time control of cooling or heating is possible.

\section{EXPERIMENTAL SETUP}

\subsection{Experimental Arrangement}

For the experimental investigation of the flow and temperature fields, an existing experimental setup with a 350 litre fermentation tank with a conical bottom shape will be used (Fig. 1).

a)
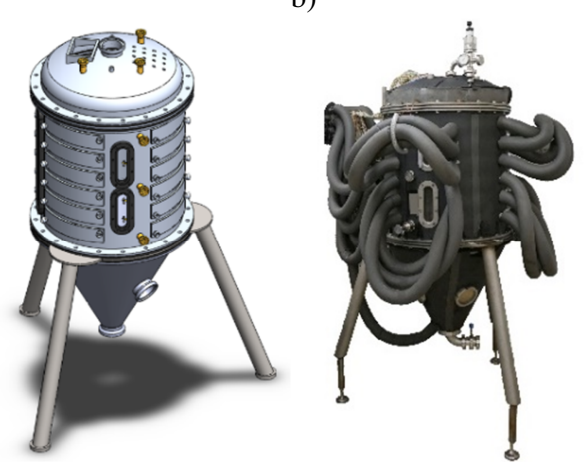

Fig. 1 Fermentation tank with conical bottom shape; a) design drawing, b) insulated and equipped tank

Several openings in the fermentation tank allows the integration of temperature sensors for the temperature field measurement and transducers for the flow field measurement. For a defined managed fermentation process the tank is equipped with six separately controlled cooling or heating zones and one additional zone in the bottom. To control the cooling zones during the fermentation and maturation process, a new completely re-engineered program was created on the software tool "LabView". In this study, the program is used to hold predefined temperatures.

\subsection{Implementation of the temperature measurement}

The temperature measurement arrangement for this study is carried out by a conventional measuring method in a grid array of 58 resistance temperature detectors (RTD). The measured values are recorded via multiplexer cards and are processed in LabView and can then be evaluated graphically.

The installed temperature sensors in the grid of the fermentation tank are shown in Fig. 2.

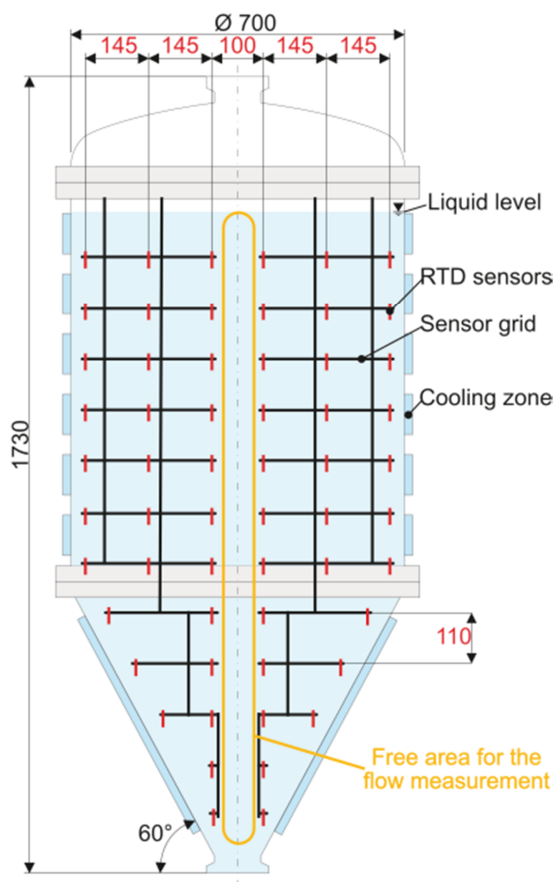

Fig. 2 Implementation of temperature sensors in a grid and resulting measuring field in the cylindrical part and in the conical bottom shape

\subsection{Uncertainty and calibration of temperature sensors}

PT1000 temperature sensors were used to measure the temperature as accurately as possible. The temperature sensors are connected in 4-wire mode to minimise the error due to different cable lengths. The accuracy class of the temperature sensors corresponds to $1 / 3$ DIN and thus corresponds to the former accuracy class AA. For the current investigation, the exact measurement within a row was relevant in addition to the measurement of the tank temperature. For this reason, the sensors were calibrated row by row and thus achieve a relative deviation of $\pm 0.04^{\circ} \mathrm{C}$ and a deviation of $\pm 0.13^{\circ} \mathrm{C}$ seen across the tank. 


\subsection{Implementation of the flow measurement}

The difficulties of a flow investigation with a biological fermentation fluid (wort) are the many complex interactions between the different three phases (yeast as a solid, carbon dioxide bubbles as a gas, wort as a fluid). Furthermore, natural convection processes are superimposed by rising gas bubbles and the distribution of the yeast. Finally, the high turbidity of the fluid only allows acoustic or magnetic resonance tomography velocity measurements [9-13]. This leads to high requirements for the measurement technology and the following evaluation. In this case, the Ultrasonic Doppler Velocimetry are used. The measurement of the flow field is carried out by means of the Ultrasonic Velocity Profile Monitor System according to an idea of Takeda from $1991[9,12]$.

To reduce interference and for higher accuracy, this study combines two coupled UDV systems for a high-resolution velocity field with two different frequencies ( $2 \mathrm{MHz}, 4 \mathrm{MHz}$ ). The transducers are implemented with small sleeves, in the bottom shape (Fig. 3 in the lower part). The new implementation allows a cartesian grid not only in the cylindrical part but also in the bottom shape. The experimental setup consists of a velocity field array of $19 \times 4 \mathrm{MHz}$, $16 \times 2 \mathrm{MHz}$ transducers and enables an improved resolution compared to the previous measurements. The velocity measuring array are shown in Fig. 3.

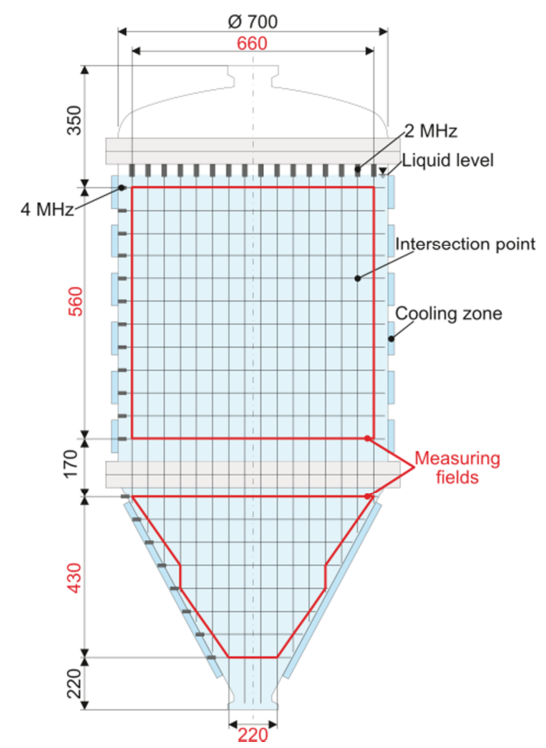

Fig. 3 Implementation of transducers and resulting velocity measuring fields (intersection points) in the cylindrical part and in the conical bottom shape

The properties of the measuring field are shown in Tab. 1. In the new arrangement, are 192 intersection points in the cylindrical part and additional 80 intersection points in the conical bottom.

Each intersection point represented in Tab. 1 consists of three-dimensional measuring volume in the form of two combined truncated cones or in simplified form of two disks.

Tab. 1 Properties of the measuring fields

\begin{tabular}{ccc}
\hline Measuring fields & Cylindrical part & Conical bottom \\
\hline Transducer & \multicolumn{3}{c}{16} \\
$(2 \mathrm{mhz})$ & (cylindrical part and bottom shape) \\
Transducer & 12 & 8 \\
$(4 \mathrm{mhz})$ & 192 & 80 \\
\hline Intersection points & & \\
\hline
\end{tabular}

The resulting velocities for each intersection of these two disks are calculated with another self-written program for quick evaluation of the UDV data. The two raw data of the UDV systems ( $2 \mathrm{MHz}$ and $4 \mathrm{MHz}$ ) can thus be read and processed. In a first step, the program reduces or eliminates errors caused by gas bubbles, shading effects or definitely incorrect measurements. In a second step, all velocities are compared with the correct intersection points and the resulting velocities vectors in a cartesian grid are calculated. The last step is to create an output file for the visualisation software.

\subsection{Uncertainties of the velocity measurement}

The theoretical verification of the measurement accuracy of the flow using the UVP method was carried out by several researchers. Ohkubo et al. [14] discussed the error caused by discretisation of the measuring point and discontinuity of the flow. They came to the conclusion that with a sufficient number of data points in the flow area and a careful averaging time with regard to the temporal properties of the flow, an overall measurement accuracy of the flow of significantly less than $1 \%$ can be achieved. Kikura et al. [15] discussed the error that exceeded the measurement volume determined by beam size and pulse length. They came to the conclusion that this error is also about $1 \%$.

The calibration results for the flow measurement according to the UVP method at the national standard are from Tezuka et al. [16] They reported that a deviation from the reference flow was only $-0.53 \%$ to $0.42 \%$.

Own investigations have shown larger deviations. However, the aim of the investigations was to determine the influence of single bubbles, bubble columns and bubble swarms on the UDV measurement technique [17-19]. The two-phase flow was investigated in a bubble tower with the PIV and the UDV. The accuracy of the UDV measurement strongly depended on the maximum measurable depth, the velocity resolution and the velocity range. Basically, the measurements with the UDV in the first third of the maximum measurable depth are the most accurate (1.5\% deviation from the PIV). Furthermore, the Nyquist-Shannon effect must be considered during implementation in the fermentation tank. 
Taking into account temperature fluctuations of approx. $\pm 0.5 \mathrm{~K}$, the resulting uncertainties in the determination of the measurement depth were approx. $1.5 \mathrm{~mm}$ (2 $\mathrm{MHz}$ Transducer) $/ 0.9 \mathrm{~mm}$ (4 $\mathrm{MHz}$ Transducer) due to the corresponding sound velocity changes. The mean velocity profiles were calculated averaging 355 (2 MHz Transducer)/235 (4 MHz Transducer) single profiles, which corresponds to a measurement time of approx. 9.3/5.4 s. On the basis of the investigations in the fermentation tank, a measurement accuracy of $98 \%$ can be assumed for the selected model fluid.

\subsection{Implementation of the thermal circuit}

The aim of the new laboratory setup was the error-free and efficient implementation of an additional heating circuit [8].

The initial point was the already existing cooling circuit with a $10 \mathrm{~kW}$ climate control and eight separately controllable cooling jackets. To this an open heating circuit was designed with a pump that can supply all 8 jackets/zones to be heated and has power reserves for any subsequent changes to the circuit.

The selected pump has an output of 2200 watts and can deliver a maximum pressure of 4 bar. The maximum flow rate is 180 litres per minute.

A total of 16 motor-driven three-way valves ( 8 inlet and 8 outlet) are used to switch between heating and cooling circuits. These can be actuated by an external signal, which is made by a voltage change from the control computer via the analog output module to the valve.

A bypass with 2 motor-driven two-way valves is provided to protect the system. The heating of the glysantine-water mixture takes place in a tank with a capacity of 30 litres and an output of 6400 watt. The desired temperature can be set on a digital control panel with an accuracy of $\pm 0.5 \mathrm{~K}$. The complete structure of the heating and cooling circuit is shown in Fig. 4.

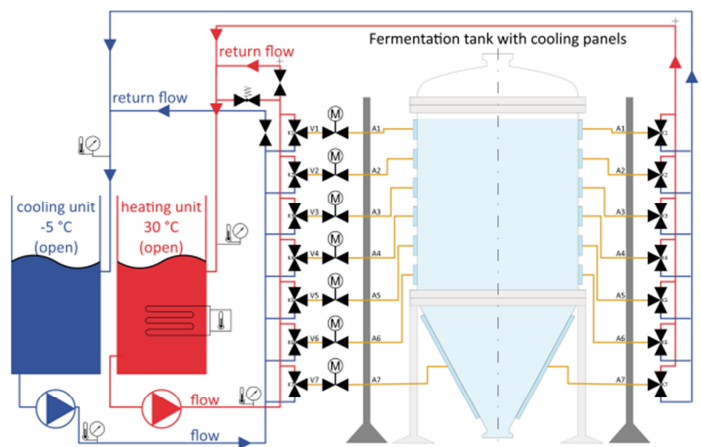

symbol description:

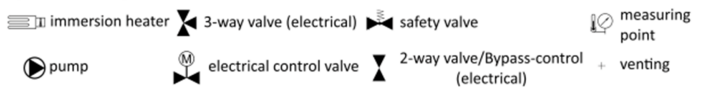

Fig. 4 Schematic structure of the thermal and cooling circuit

\subsection{Physical properties of the investigated fluid}

Due to the high complexity of a multi-phase flow, this paper examines the natural convection flow with a model fluid. For the physical properties of the model fluid, the experimental results are shown in Tab. 2. The same physical properties will be used for the numerical simulation. The properties of the model liquid/water were assumed to be the reference value of $10{ }^{\circ} \mathrm{C}$. In this temperature range, cold fermentation is also carried out during real fermentation.

Tab. 2 Physical properties of the fluid $\left(10^{\circ} \mathrm{C}\right)$

\begin{tabular}{ll}
\hline Physical properties & Value \\
\hline Density $\left[\mathrm{kg} / \mathrm{m}^{3}\right]$ & 999.70 \\
Dynamic viscosity $[\mathrm{kg} /(\mathrm{m} \cdot \mathrm{s})]$ & $1306.4 \mathrm{e}-6$ \\
Specific heat capacity $[\mathrm{j} /(\mathrm{kg} \cdot \mathrm{k})]$ & 4192 \\
Thermal conductivity $[\mathrm{w} /(\mathrm{m} \cdot \mathrm{k})]$ & 0.566 \\
Thermal diffusivity $\left[\mathrm{m}^{2} / \mathrm{s}\right]$ & $1.38 \mathrm{e}-7$ \\
\hline
\end{tabular}

Important for measurements with the Ultrasonic Doppler Velocimetry is the sound velocity at the time of measurement. For an accurate measurement of the sound velocity, an additional measurement system based on a transit time difference method is used.

\section{DIMENSIONLESS NUMBERS}

To compare similar flow processes, dimensionless numbers are quite useful. The most important dimensionless numbers for the natural convection flow are listed below in Tab. 3. These dimensionless numbers were calculated on the basis of Tab. 2 and refer to the real fermentation process in a fermentation tank, at the cold fermentation. The characteristic temperature and length for the Grashof number was measured during fermentation and corresponds to the length between the upper cooling jackets and the sedimented yeast (heat) in the conical bottom shape.

Tab. 3 Dimensionless numbers

\begin{tabular}{cccc}
\hline \multicolumn{2}{c}{ Number } & Relevant parameters & Value \\
\hline $\mathrm{Pr}$ & $\begin{array}{c}\text { Prandtl } \\
\text { Grashof } \\
\text { (case 1) }\end{array}$ & $\begin{array}{c}\Delta \mathrm{t}_{\mathrm{v}}=9 \mathrm{k} \\
\mathrm{L}=1.375 \mathrm{~m}\end{array}$ & 4.16 \\
$\mathrm{Gr}_{1}$ & $\begin{array}{c}\Delta \mathrm{t}_{\mathrm{v}}=24 \mathrm{k} \\
\mathrm{Gr}_{2}\end{array}$ & $\begin{array}{c}\text { Grashof } \\
\text { (case 2) }\end{array}$ & $\mathrm{L}=1.375 \mathrm{~m}$ \\
$\mathrm{Ra}_{1}$ & $\begin{array}{c}\text { Rayleigh } \\
\text { (case 1) }\end{array}$ & $1.24 \mathrm{e} 11$ \\
$\mathrm{Ra}_{2}$ & $\begin{array}{c}\text { Rayleigh } \\
\text { (case 2) }\end{array}$ & $3.34 \mathrm{e} 11$ \\
$\mathrm{Nu}$ & Nusselt & $\mathrm{a}=1200 \mathrm{w} /\left(\mathrm{m}^{2} \cdot \mathrm{k}\right)$ & 324 \\
\hline
\end{tabular}




\section{NUMERICAL SETUP}

\subsection{Meshing}

For a practical comparison of the simulated natural convection flow and the experimental measurement, the simulation must also be calculated threedimensionally. The mesh of the fermentation tank is shown in Fig. 5.

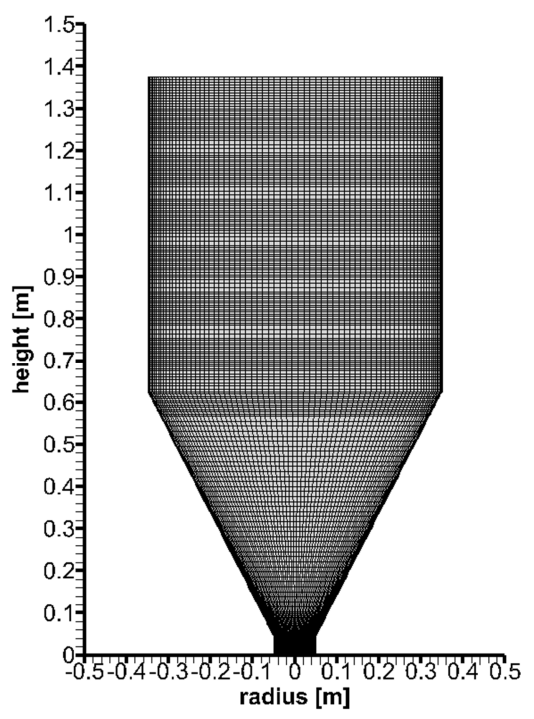

Fig. 5 Meshing of the fermentation tank (front view)

The mesh was created with ICEM and is a complete hexahedron mesh. The corresponding mesh metric and quality is shown in Tab. 4.

Tab. 4 Mesh quality and metric of the three-dimensional mesh of the fermentation tank

\begin{tabular}{|c|c|c|}
\hline \multicolumn{3}{|c|}{ Mesh Quality Metrics (264735 Elements) } \\
\hline Skewness & Min & $1.30 \mathrm{e}-5$ \\
\hline & Max & 0.32 \\
\hline & Average & $7.58 \mathrm{e}-2$ \\
\hline \multirow[t]{3}{*}{ Orthogonal Quality } & Min & 0.87 \\
\hline & $\operatorname{Max}$ & 1 \\
\hline & Average & 0.98 \\
\hline
\end{tabular}

\subsection{Boundary Conditions}

Correct boundary conditions are important for a realistic simulation. The numerical boundary conditions are exactly coordinated to the experimental boundary conditions. Due to the differences in density, the yeast sediments in a bottom-fermented beer in the course of fermentation and thus warms the cone bottom. For this reason, in both cases the heat is generated in the conical bottom shape and the cooling takes place in the upper cooling jacket. The first Boundary conditions for the simulation and the experiment in this study are shown in Fig. 6 and the second boundary conditions for the simulation and the experiment in Fig. 7. The first boundary condition is the normal case in real fermentation. With the second case, the boundary conditions are now changed so that a temperature layering should occur. These changed boundary conditions should generate an additional flow layer in the middle of the tank by means of the additional heat and cooling.

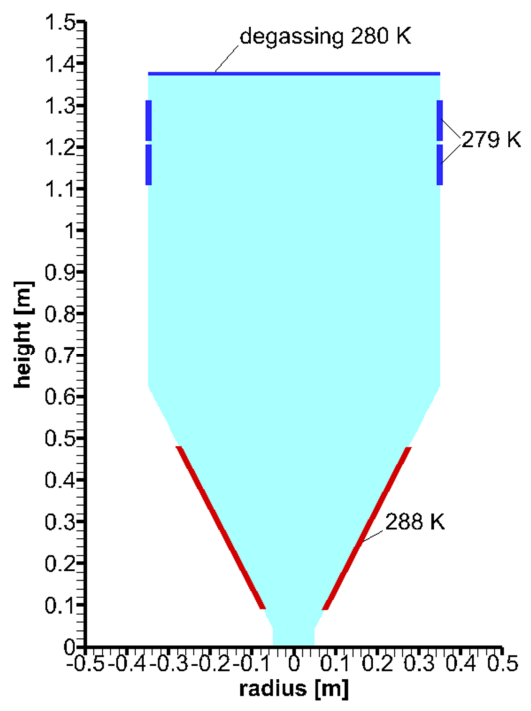

Fig. 6 Boundary conditions in the first case

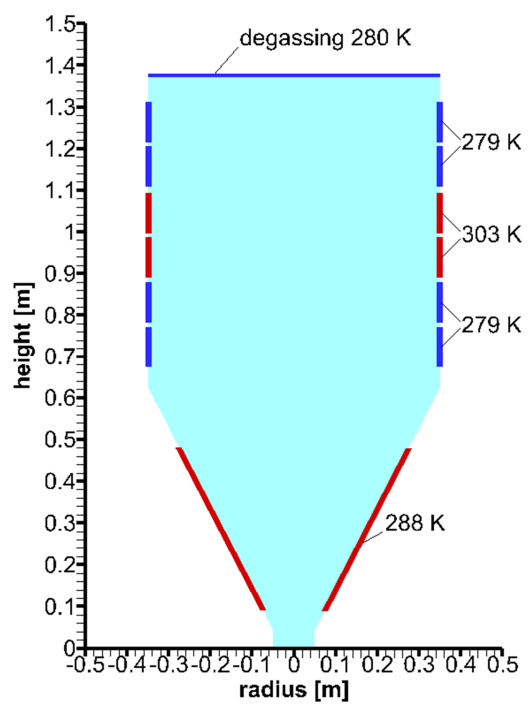

Fig. 7 Boundary conditions in the second case

\subsection{Description of the numerical simulation}

The numerical simulation was created with Fluent (ANSYS). The meshing was created as described in the chapter 4.1. For the simulation of the natural convection the energy equation was used. For the modelling of the model liquid the values from Tab. 2 were used. Turbulence modelling was performed using the k- $\omega$-SST turbulence model. In the first step, a stationary simulation was created and later served as 
an initialisation solution for the transient simulation. With the transient simulation large time steps $(t>50 \mathrm{~s})$ had to be used at the beginning and finally time steps of $10 \mathrm{~s}$ could be used.

\subsection{Simulation of the natural convection flow}

The natural convection in an open region usually has no problems to converge, but a calculation in a closed region requires a special consideration in order to converge. In the first step, the natural convection in a closed region is defined that the mass is constant. In the next step, a distinction is made between a steady and a transient calculation. [20-27].

In a steady calculation, the mass in the system does not change over time and is determined by the initial value. The possible density settings for a transient simulation of the natural convection flow are the Boussinesq model, the incompressible ideal gas law and compressible ideal gas law.

The Boussinesq model assumes a constant density, so mass conservation is automatically true. In contrast, the incompressible ideal gas law assumes a constant reference pressure and so mass is not conserved. The compressible ideal gas law sets density to be a function of local pressure, so mass is conserved.

For a transient calculation, the Boussinesq model is usually recommended and a calculation starts with a large time step if the intermediate history of the flow field is not required. Another method to describe a natural convection process is to use a User Defined Function. This approach expands the Boussinesq model by adding natural convection as a User Defined Function while density is kept constant on the material definition. This would not be necessary if the coefficient of thermal expansion of water is always constant, which corresponds to the standard Boussinesq feature. However, if the coefficient of thermal expansion changes, the direct physical force should be determined with UDF, as in the fermenter.

The programmed User Defined Function calculates a direct body force and includes a 6th order polynomial for the density changes, thereby reducing the error of the Boussinesq model [3].

\section{RESULTS AND DISCUSSION}

\subsection{Results of the temperature fields}

The temperature field was measured continuously every five minutes [28]. The thermal boundary conditions of the investigation were adapted to the real brewing process and are described in Chapter 3.2. In the first case only the two upper cooling zones (flow temperature approx. $6^{\circ} \mathrm{C}$ ) are cooled and the heat is generated in the conical bottom shape (flow temperature approx. $15^{\circ} \mathrm{C}$ ). The experimental temperature field of the cylindrical tank with the conical bottom shape is shown in Fig. 8 and the numerical temperature field in Fig. 9.

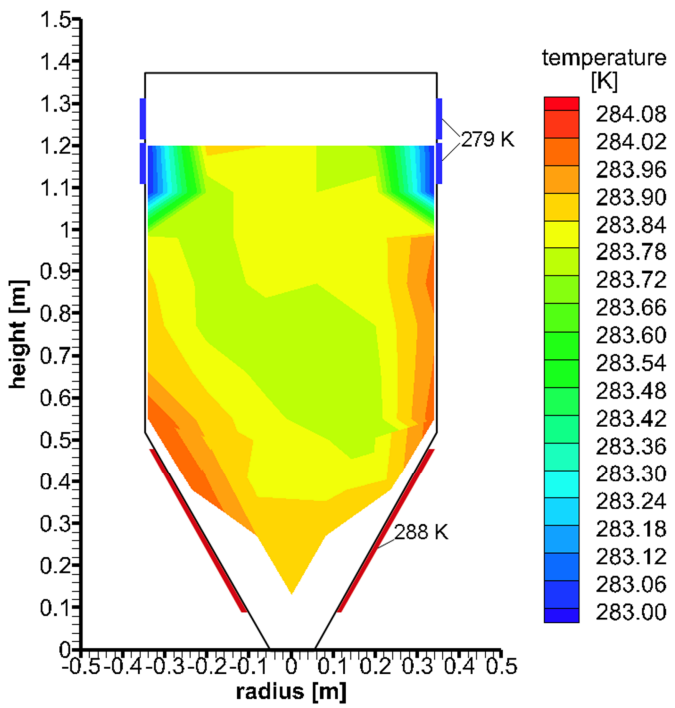

Fig. 8 Temperature field inside the cylindrical tank with conical bottom in the first case, experimental result after 1 hour

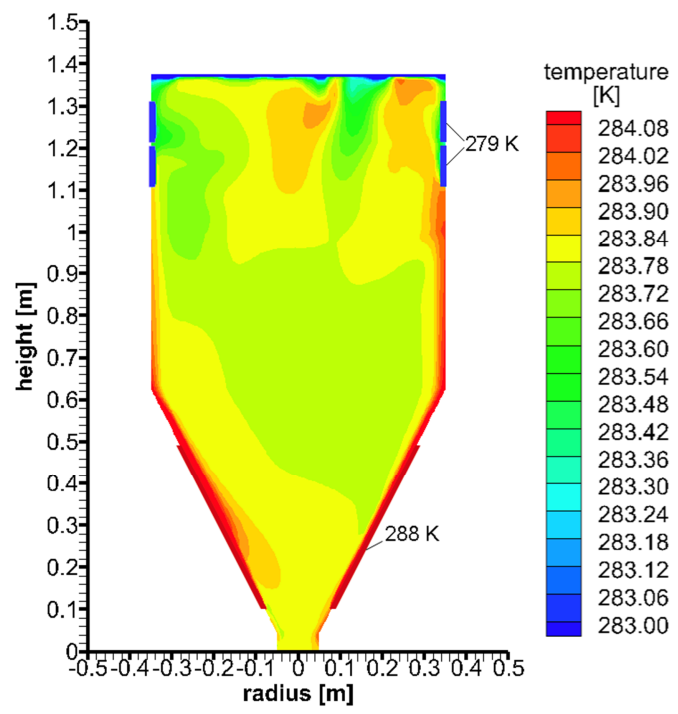

Fig. 9 Temperature field inside the cylindrical tank with conical bottom in the first case, numerical result after 1 hour

The temperature field within the first configuration shows the heating in the conical bottom shape and the cooling of the upper cooling zones. The experimental and the numerical temperature fields and values are very similar.

In the second case, the two upper cooling zones (flow temperature approx. $6^{\circ} \mathrm{C}$ ) and two additional zones near the bottom shape are cooled. The heat is now generated in the conical bottom shape and in two additional zones (flow temperature approx. $30^{\circ} \mathrm{C}$ ) in the middle of the tank. The experimental temperature field of the cylindrical tank with the conical bottom shape is shown in Fig. 10 and the numerical temperature field in Fig. 11. 


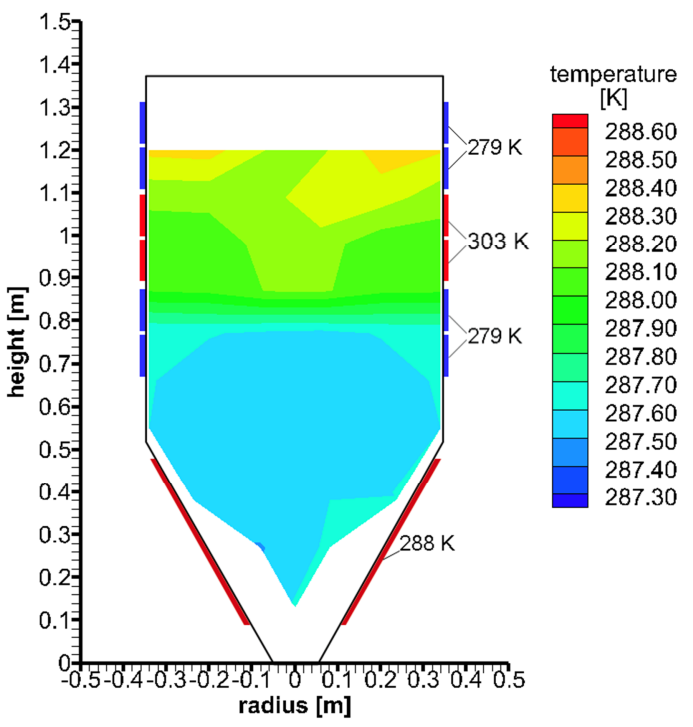

Fig. 10 Temperature field inside the cylindrical tank with conical bottom in the second case, experimental result after 30 minutes

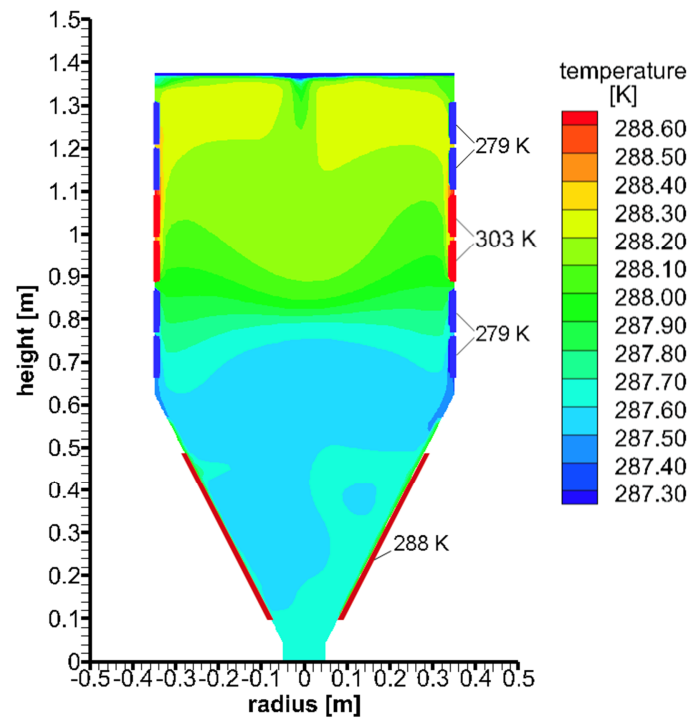

Fig. 11 Temperature field inside the cylindrical tank with conical bottom in the second case, numerical result after 30 minutes

In Fig. 10 and Fig. 11, the largest temperature difference is again near the walls. In case 2 , the temperature fields differ more strongly than in case 1 , which is due to the strongly time-dependent temperature field change.

\subsection{Measurement of flow fields}

The velocity field was measured continuously every 10 minutes. The sound velocity required for the UDV measurement system was also determined periodically by using a transit time method in the fermentation tank and averaged approx. $1486 \mathrm{~m} / \mathrm{s}$.

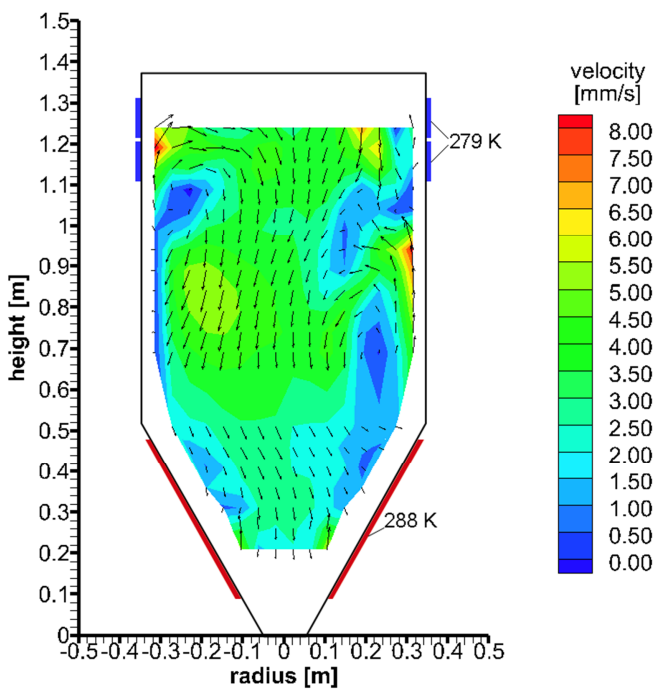

Fig. 12 Velocity field and vector plot in the cylindrical tank with conical bottom after 1 hour, UDV, first case

For the first boundary conditions (first case), Fig. 12 and Fig. 13 show the velocity fields of the fermentation tank with the conical bottom shape after one hour. Both figures show a very similar flow topology. The numerical solution shows that especially the wall areas with the greatest temperature gradient have the highest velocities. In the next investigations an improved resolution of the near-wall areas should be realised.

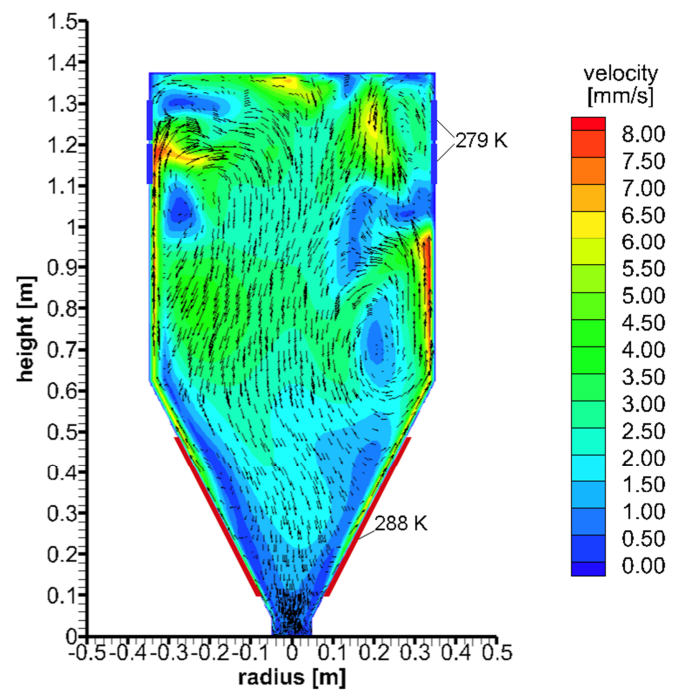

Fig. 13 Velocity field and vector plot in the cylindrical tank with conical bottom after 1 hour numerical result, first case

In Fig. 14 (experimental result with ultrasonic Doppler velocimetry) and Fig. 15 (numerical result with CFD) the velocity fields of the fermentation tank with the conical bottom shape are shown after 30 minutes, in the second case. 


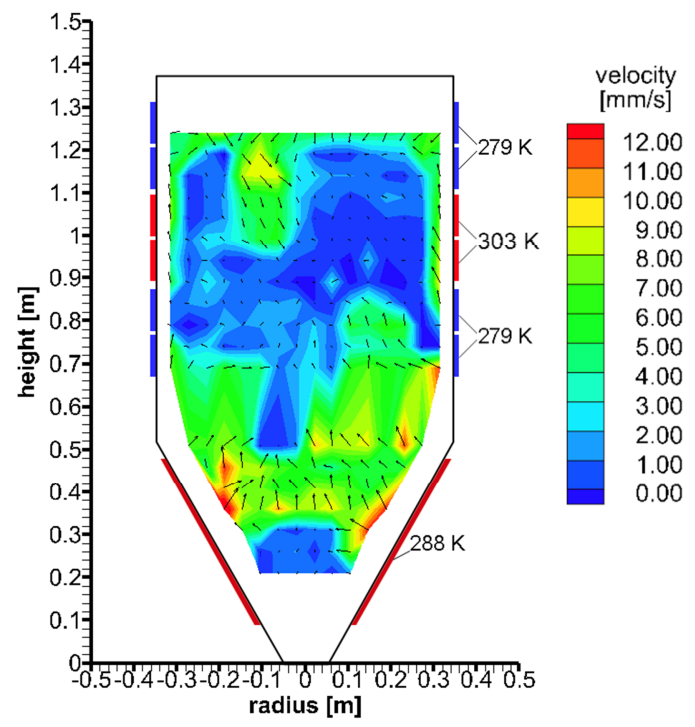

Fig. 14 Velocity field and vector plot in the cylindrical tank with conical bottom after 30 minutes, UDV, second case

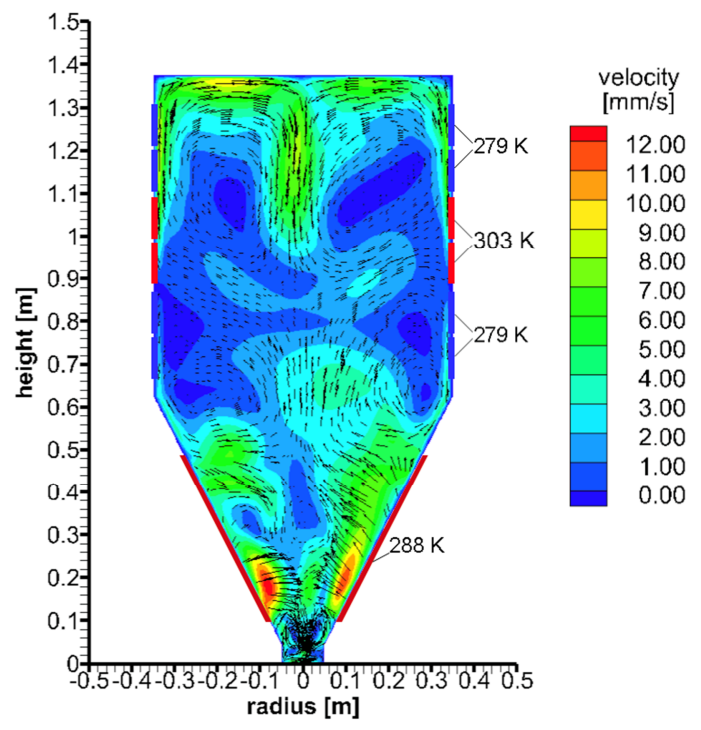

Fig. 15 Velocity field and vector plot in the cylindrical tank with conical bottom after 30 minutes, numerical result, second case

The flow topology now is different from case 1, which is influenced by the changed boundary conditions. By comparing the first case and the second case, it is noticeable that the flow has changed significantly.

In the first case, a significant spatial flow with large vortexes can be noticed. This resulting flow field is already indicated by the temperature field. The additional heating of the other cooling jackets in the middle of the fermentation tank and the cooling of the cooling jackets in the area near the bottom shape creates a thermal barrier layer. This is also indicated in the corresponding temperature profile. This layer prevents the large spatial vortexes and breaks them up for several smaller vortexes located above and below the barrier layer. In the direct comparison of the Fig. 14 and Fig. 15, slight differences in the flow velocities are noticeable, but the flow topology is still similar.

\section{CONCLUSION}

In this investigation, the temperature and velocity fields in a fermenter with a conical bottom shape in a model fluid were measured and described. The flow in the fermenter was generated by a simulated natural convection flow. In summary, the investigation has shown that the connection and evaluation of two coupled Ultrasonic Doppler measuring devices is suitable for improved resolution.

In order to improve the measurement results with Ultrasonic Doppler Velocimetry, it is recommended to induce very small gas bubbles following the flow of natural convection in the fermenter. In addition, acoustic flow particles should be used.

On the other side, the numerical simulation can be used with very good approximation, for the description of the natural convection in the fermenter. Problems with the simulation of a natural convection in a closed domain can be minimised with a User Defined Function. However, the most important point in the simulation remains the correct description of the boundary conditions.

The investigation has shown that variable boundary conditions have an effect on natural convection flow in the fermentation tank. This result can be used for a even distribution of the yeast at the beginning of the fermentation and also in later periods.

Further investigations of the yeast should show that the velocities of the natural convection are adequate to guarantee the yeast distribution. The influence of a variable natural convection flow on the movement of the gas bubbles formed during fermentation must also be investigated. The next steps of this investigation will take place with a real liquid to be fermented such as beer. The next steps in numerical simulation are the simulation of gas bubbles and particles (yeast). For more precise results, the physical properties of the beer wort will also be used in the simulation. The physical properties are to be measured by several additional measuring systems on the fermentation tank for the density, sugar concentration and sound velocity.

\section{Acknowledgements}

The authors gratefully acknowledge by the "European Regional Development Fund" (ERDF) for the financial support of the fermentation tank (FHHST23, GHS-150050) and for the measurement technique "Ultrasound Velocimetry System" (GHS170021). 


\section{Nomenclature}

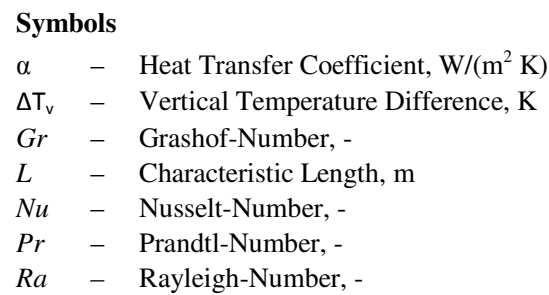

\section{Acronyms}

CFD - Computational Fluid Dynamics

PIV - Particle Image Velocimetry

UDV - Ultrasonic Doppler Velocimetry

\section{References}

1. Delgado A., Hartmann C., Baars A., Meironke H., Szymczyk J. A. (2004). Bewegung im Gärtank: Messtechnische Diagnose und Simulation, Tagungsband Brautechnologisches Seminar, Freising.

2. Klembt D., Meironke H. (2019). Numerical approaches for the yeast distribution in a fermentation tank. PAMM Proceeding Applied Mathematics Mechanics, e201900116. doi: 10.1002/pamm.201900116, Vienna.

3. Klembt D., Meironke H. (2017) Numerical approaches for simulation of a biological multiphase flow inside real fermentation tanks, In Proceedings XXIII. International Symposium „Research-Education-Technology”, Vol. 23, ISBN 978-3-9817740-2-3, pp. 73-80.

4. Klembt D., Meironke H. (2018). Numerical approaches for the simulation of a real multiphase flow in a fermentation tank, Proceeding Applied Mathematics Mechanics, e201800258. doi:10.1002/pamm.201800258, Munich.

5. Klembt D., Meironke H. (2018) Experimental investigations of the influence of different bottom shapes on the temperature and velocity fields in a fermentation tank with a biological multiphase flow, In Proceedings 11. International Symposium on Ultrasonic Doppler Methods for Fluid Mechanics and Fluid Engineering, doi: 10.7795/810.20190809, Berlin.

6. Heyse, K.-U. (1995). Handbuch der Brauerei-Praxis. Getränke-Fachverlag Hans Carl, Vol. 3, ISBN 3-41800736-8, Weihert-Druck GmbH, Darmstadt.

7. Khosrokhavar R., Elsinga G., Farajzadeh R., Bruining H. (2014) Visualization and investigation of natural convection flow of $\mathrm{CO} 2$ in aqueous and oleic systems, Journal of Petroleum Science and Engineering, Vol. 122, ISSN 0920-4105, pp. 230-239.

8. Crabb D., Maule D. R. (2001). Temperature control and yeast sedimentation characteristics in large storage vessels, E.B.C. fermentation and storage symposium, Zoeterwoude, pp. 168-180.

9. Takeda Y. (2012). Ultrasonic Doppler Velocity Profiler for Fluid Flow, Springer, ISBN 978-4-431-54025-0.

10. Koch S. (1992). Non-intrusive measurement of temperature and velocity in free convection, ISSN 0374 1257, PhD University Göttingen.

11. Becker T. (2001). Ultrasonic velocity - a non-invasive method for determination of density during beer fermentation, Journal of Engineering in Life Sciences, Vol. 2, pp. 61-67.

12. Takeda Y. (1986). Velocity profile measurement by ultrasound Doppler shift method, International Journal of Heat and Fluid Flow, Vol. 7, No. 4, pp. 313-318.

13. Park H., Park J., Jung S. Y. (2019). Measurements of velocity and temperature fields in natural convective flows, International Journal of Heat and Mass Transfer, Vol. 139, ISSN 0017-9310, Pages 293-302.

14. Ohkubo T., Takeda Y. (2006). Accuracy evaluation of high-accuracy flowmeter using UVP. Japan Society of Mechanical Engineering, Series B, pp. 81-89, Japan.

15. Kikura H., Yamanaka K., Aritomi M. (2004). Effect of measurement volume on turbulent flow measurement using ultrasonic Doppler method. In Experiments in Fluids, Vol. 36, doi: 10.1007/s00348-003-0694-x, Japan.

16. Tezuka K., Mori M., Suzuki T., Takeda Y. (2008). Calibration tests of pulse-Doppler flow meter at national standards loops, In Flow Measurement and Instrumentation, Vol. 19, pp. 181-187.

17. Meironke, H. and Klembt, D. and Panten, T. (2017). Untersuchungen zum Einfluss von Gasblasen auf die Ultraschall Doppler Messtechnik mittels optischer und numerischer Methoden. In GALA - Deutsche Gesellschaft für Laser-Anemometrie -, Vol. 25, ISBN 978-3-9816764-3-3, pp. 45/1-45/8, Karlsruhe.

18. Klembt, D. and Meironke, H. and Pommer, E. (2018). Untersuchungen zum Einfluss von Blasensäulen auf die Ultraschall Doppler Messtechnik. In GALA - Deutsche Gesellschaft für Laser-Anemometrie -, Vol. 26, ISBN 978-3-9816764-5-7, pp. 7/1-7/8, Rostock.

19. Klembt, D. and Meironke, H. and Delgado, A. (2019). Untersuchungen zum Einfluss von Blasenschwärmen und -säulen auf die Ultraschall Doppler Messtechnik. In GALA - Deutsche Gesellschaft für Laser-Anemometrie -, Vol. 27, ISBN 978-3-9816764-6-4, pp. 11/1-11/9, Erlangen.

20. Michalek T., Kowalewski T.A. (2005). Natural convection for anomalous density variation of water: Numerical benchmark. In Progress in CFD, Vol. 5.

21. Banaszek J., Jaluria Y., Kowalewski T. A., Rebow M. (1999). Semi-implicit FEM analysis of natural convection in freezing water. Numerical Heat Transfer, Part A, Vol. 36, No. 5, pp. 449-472.

22. Kowalewski T. A., Rebow M. (1999). Freezing of water in a differentially heated cubic cavity. International Journal of Computational Fluid Dynamics, Vol. 11, Nos. 3-4, pp. 193-210.

23. Leonardi E., Kowalewski T.A., Timchenko V., de Vahl Davis G. (1999). Effects of finite wall conductivity on flow structures in natural convection. CHMT99 Proceedings of International Conference Computational Heat and Mass Transfer, Eastern Mediterranean University Printinghouse, Cyprus, pp. 182-188.

24. Dol H. (1998). Turbulence Models for natural convection in side-heated enclosures, International Journal of Heat and Mass Transfer, Vol 44, pp. 2323-2344, doi:10.1016/S0017-9310(00)00271-4.

25. Nurzynski M. (2004). Numerical investigations of fluidmechanics inside cylindroconical fermentation tanks, Diploma Thesis, Gdansk University of Technology.

26. Le Quéré P., Weisman, C., Paillère H., Vierendeels J., Dick E., Becker R., Locke J. (2005). Modelling of Natural Convection Flows with Large Temperature Differences: A Benchmark Problem for Low Mach Number Solvers. Part 1. Reference Solutions. ESAIM: Mathematical Modelling and Numerical Analysis, 39(3), doi:10.1051/m2an:2005027, pp. 609-616.

27. Gandhi M. A., Sathe M. J., Joshi J. B., Vijayan P. K. (2011). Two phase natural convection: CFD simulations and PIV measurement, Chemical Engineering Science, Vol. 66, Issue 14, ISSN 0009-2509, pp. 3152-3171.

28. Hiller W., Kowalewski T. A. (1987). Simultaneous measurement of temperature and velocity fields in thermal convective flows. In Flow Visualization IV. $C$. Veret, Ed., pp. 617-622. Hemisphere, Paris. 


\section{Biographical notes}

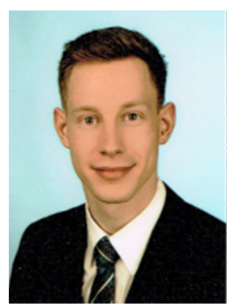

Daniel Klembt is a mechanical engineer and is currently completing his doctoral degree (Dr.-Ing.) on real biological multiphase flows at the University Erlangen-Nürnberg. Since 2017 he has been a research assistant at the Department of Fluid Mechanics and Apparatus Engineering at the University of Applied Sciences Stralsund. His scientific interests are in the fields of acoustic velocity profile measurement, optical measurement techniques, numerical simulation and generally the investigation of real multiphase flows. He participated in 5 international and 3 national conferences where he presented the results of his work and has published more than 10 scientific papers in international and national journals, book chapters and conference reports.

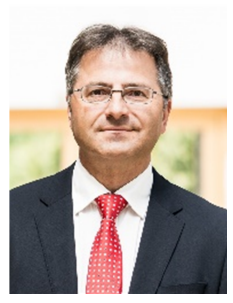

Heiko Meironke received his doctoral degree (Dr.-Ing.) at the University of Rostock in the Faculty of Mechanical Engineering and Shipbuilding Technology, specialising in applied mechanics, and is currently professor at the University of Applied Sciences Stralsund. Since 2009 he is Head of the Department of Fluid Mechanics and Apparatus Engineering at the University of Applied Sciences Stralsund. His scientific interests are the investigation of general fluid mechanics problems, in particular the experimental and numerical investigation of multiphase flows in fermenting fluids. He has presented these topics regularly at several national and international conferences and has published the results in several conference proceedings and journals. 